\title{
Evaluations of end of life with dementia by families in Dutch and U.S. nursing homes
}

\author{
Jenny T. van der Steen, 1,2,3 Marie-José H. E. Gijsberts, 1,2,3 Martien T. Muller, ${ }^{2}$ \\ Luc Deliens $s^{1,3,4}$ and Ladislav Volicer ${ }^{5}$ \\ ${ }^{1}$ EMGO Institute, VU University Medical Center, Amsterdam, The Netherlands \\ ${ }^{2}$ Department of Nursing Home Medicine, VU University Medical Center, Amsterdam, The Netherlands \\ ${ }^{3}$ Department of Public and Occupational Health, VU University Medical Center, Amsterdam, The Netherlands \\ ${ }^{4}$ End-of-Life Care Research Group, Vrije Universiteit Brussels, Brussels, Belgium \\ ${ }^{5}$ School of Aging Studies, University of South Florida, Tampa, U.S.A. and Charles University Medical School, Prague, Czech Republic
}

ABSTRACT

Background: The End-of-Life in Dementia (EOLD) scales comprise the most specific set of instruments developed for evaluations of patients' end of life by their families. It is not known whether the EOLD scales are useful for cross-national comparisons.

Methods: We used a mortality follow-back design in multi-center studies in the Netherlands (pilot study 20052007) and the U.S.A. (1999), and we compared EOLD Satisfaction With Care (SWC; last three months of life), Symptom Management (SM; last three months) and Comfort Assessment in Dying (CAD) scores for 54 Dutch and 76 U.S. nursing home residents.

Results: SWC total scores did not differ significantly between the Dutch and U.S. studies (31.9, SD 4.7 versus 30.4 , SD 6.1), but three of ten items were rated more favorable for Dutch residents, as were SM total scores (29.1, SD 9.2 versus 20.4, SD 10.6). CAD total scores did not differ (32.0, SD 5.4 versus 30.5, SD 5.9, respectively), but the "well-being" subscale was rated more favorably for Dutch residents. Results were similar after adjustment for demographics and dementia severity.

Conclusion: The Dutch families rated end of life with dementia in nursing homes as somewhat better than did U.S. families. Although differences were small, the observed patterns were consistent. This suggests validity of the SM and CAD to assess differences in quality of dying and possible sensitivity to differences between countries or time frames. Larger, simultaneous, cross-national studies are needed to confirm usefulness of the scales and to detect areas which need improvement in the respective countries.

Key words: dementia, nursing homes, end of life, EOLD scales, satisfaction, terminal care, palliative care

\section{Introduction}

In Western countries, many people die with dementia and most die in nursing homes (Mitchell et al., 2005). At least 27 quantitative studies on end of life with dementia have been published prior to 2008. Almost all were small and/or retrospective. Most were conducted in the U.S.A., and some in Canada, the U.K., Italy, Israel, Switzerland, Spain, and the Netherlands (van der Steen et al., 2007a; 2007b). These studies cannot be compared directly

Correspondence should be addressed to: Dr. Jenny T. van der Steen, VU University Medical Center, EMGO Institute, Departments of Nursing Home Medicine, and Public and Occupational Health, van der Boechorststraat 7, 1081 BT Amsterdam, The Netherlands. Phone: + 31-20-4449694; Fax: + 3120-4448387. Email: j.vandersteen@vumc.nl. Received 21 Jul 2008; revison requested 6 Oct 2008; revised version received 30 Oct 2008; accepted 3 Nov 2008. First published online 5 February 2009. due to the use of different design and measurement instruments, yet direct comparison would be useful to identify those areas where care can be improved (van der Steen et al., 2008a).

Further, validity of the instruments in dementia patients has not always been tested (Teno, 2000; Steel et al., 2003), is uncertain (Hearn and Higginson, 1999; Brandt et al., 2005), or the instruments were not developed for evaluating the last days of life specifically (Steel et al., 2003; Aminoff et al., 2004). Development of a measure of Quality of Dying in Long-Term Care (QODLTC) explicitly considered validity in residents with cognitive impairment (Munn et al., 2007; Caprio et al., 2008), but the most comprehensive and most specific set of instruments specific to assess end of life with dementia are the End-of-Life in Dementia (EOLD) scales (Volicer et al., 2001; 2003). 
The EOLD scales include the "Satisfaction With Care" (SWC), "Symptom Management" (SM) and "Comfort Assessment in Dying" (CAD) scales which were originally rated by family caregivers using a written survey (Volicer et al., 2001; 2003). We regard the SM and CAD scales as outcomes rather than process (quality of care) measures, while the SWC addresses both - satisfaction being an outcome and specific items addressing quality of care issues (Stewart et al., 1999; Hales et al., 2008). The EOLD scales were sensitive to differences across national settings: in the U.S.A., end-of-life care at home was evaluated as better than end of life in nursing homes or in hospitals (Volicer et al., 2003). They are used in ongoing prospective studies in the U.S.A. and the Netherlands (Engel et al., 2006; Kiely et al., 2006; Mitchell et al., 2006; van der Steen et al., 2007a; 2008b). However, there have not been any cross-national comparative studies to test if the EOLD total and item scores are sensitive to differences between countries in similar institutional settings and if such differences could be interpreted in terms of care elements that need improvement in these countries.

Cross-nationally, end-of-life care for residents can vary widely. For example, studies on pneumonia in nursing home residents with dementia identified major differences between U.S. and Dutch care (van der Steen et al., 2004; Helton et al., 2006). Dutch nursing home physicians are on-staff and usually know the residents and their family well, long before the death is imminent (Hoek et al., 2000; Helton et al., 2006). Decisions to withhold curative treatment were more frequent for Dutch than for U.S. residents. Nevertheless, most types of treatments to relieve symptoms were used sparingly among U.S. (Missouri) and Dutch residents with pneumonia and dementia, but dying Dutch residents did receive morphine frequently (van der Steen et al., $2004 ; 2007 \mathrm{c}$ ). Instruments evaluating end of life with dementia may reflect such differences between countries.

In this pilot study, we evaluated end-of-life experiences of Dutch nursing home residents and compared them with earlier collected data from U.S. residents who had died with dementia using family ratings of EOLD scales, to detect differences between the two studies. We additionally explored association of the EOLD scales with some other variables.

\section{Methods}

\section{The two studies}

The Dutch study was performed in four nursing homes as a pilot for a larger ongoing prospective study (van der Steen et al., 2007a; 2008b). Data were collected between November 2005 and July 2007. Participating homes were an urban and a rural traditional home, and an urban and a rural "anthroposophic" home. Anthroposophy is a philosophy of life in which dying is considered as a transition to another form of life, a birth into the spiritual world. As well as supporting symptom management, palliative anthroposophic care places great importance on meeting the dying person's emotional, social and spiritual needs, possibly even more so than traditional palliative care systems. EOLD SM and CAD scores, but not the SWC scores, have been shown to be more favorable in relation to anthroposophic nursing homes (Gijsberts et al., 2008).

Nurses identified the family caregiver who had been most involved in the last months of life of each resident with dementia (as diagnosed by a physician) who had died within the period of data collection. Questionnaires were completed about two months after death. Family caregivers were provided with a mailed questionnaire including the EOLD items. The response rate was $61 \%(54 / 89)$. The study protocol was approved by the Medical Ethics Committee of the VU University Medical Center in Amsterdam.

The U.S. study is described in more detail elsewhere (Volicer et al., 2001; 2003). The data of this national study were collected between January and June 1999, and have been used to develop the EOLD. Families of residents with dementia whose relatives had died in the preceding year completed a mailed or handed out questionnaire that included all EOLD items. For the purpose of the comparison, we selected 76 U.S. residents who died in a nursing home.

Dementia severity was measured by the Bedford Alzheimer Nursing-Severity (BANS-S) comprising seven items. Total scores range from 7 to 28 (Volicer et al., 1994; Bellelli et al., 1997). In the U.S. study, families completed the BANS-S while in the Dutch study it was completed by nurses. Items are straightforward (e.g. eating dependency, eye contact) and reflected status 90 days before death.

\section{The EOLD scales}

The SWC scale has ten items with four response options scored 1 to 4 ; total scores are sums of item scores with a range from 10 to 40,40 representing highest satisfaction. The SM scale has six response options ( 0 to 5 ); nine items are summed to calculate a total score ranging from 0 to 45 (best symptom management). Eight items reflect symptoms or other negative conditions; one item is a positive condition ("calm"). The CAD scale has three response options (scored 1 to 3) 
with 14 items; summed total scores range from 14 to 42. The CAD comprises four subscales with a varying number and some overlapping items: Physical Distress, Dying Symptoms, Emotional Distress, and Well Being. For all scales, coding was reversed when applicable. A category "not applicable" was included for the SWC only in both studies. In both studies, evaluations reflected status over the last three months of life (SWC and SM) or during dying (CAD).

Psychometric properties were adequate in an independent U.S. population where nurses scored the SM and CAD in a cross-sectional sample of residents with advanced dementia (Engel et al., 2006; Kiely et al., 2006). Distributions were normal and Cronbach's $\alpha$ varied between 0.68 and 0.83 .

\section{Analyses}

To compare demographics between countries $\chi^{2}$ statistics were calculated. Item and total scores were compared between countries with independent sample t-tests and items were also tested with the non-parametrical Mann-Whitney U-test. A significance level of 0.01 was adopted to account for multiple comparisons for all comparisons of means between the two studies.

Additionally, linear regression with EOLD total and subscale scores as the dependent and the country as the independent was performed with adjustment for demographics and dementia severity. Adjustment for relationship with the resident was performed with dummy variables for "spouse of the resident;" we additionally tested "child of the resident" entered in separate models to avoid colinearity, but results were similar. Unstandardized beta coefficients and 95\% confidence intervals were calculated for the country variable, representing adjusted differences in scale scores between the Netherlands and the U.S.A.

We further explored associations between EOLD total scores and demographics (gender of resident and respondent, resident age, respondent being a spouse, child, or daughter) and dementia severity, adjusted for nationality, and - available in the Dutch dataset only - whether the nursing home was the respondent's or resident's nursing home of preference. We report on associations that were at least marginally significant $(p<0.10)$ because of limited power for regression analyses.

Missing BANS-S items were imputed with subject means if two or fewer. Missing SWC and SM items were imputed with subject means if three or fewer, and for the CAD, four or fewer. Only in the U.S. study were $>5 \%$ of items frequently missing. Previously published means were without imputation (Volicer et al., 2003) and therefore differ slightly from means presented in this paper. The largest difference was for the $\mathrm{CAD}$; the published CAD mean was 31.0 (standard deviation (SD), 6.2) for 44 observations ( $\mathrm{n}=54$ to 63 per item) versus 30.5, SD 5.9 for 53 observations after imputation.

\section{Results}

The Dutch nursing home residents in the study were more frequently female, and, on average, older than the U.S. residents (Table 1). Nevertheless, on average they had less severe dementia, and

Table 1. Characteristics of Dutch and U.S. nursing home residents and family caregivers

\begin{tabular}{|c|c|c|c|}
\hline & $\begin{array}{l}\text { NETHERLANDS } \\
(\mathrm{N}=54)\end{array}$ & $\begin{array}{l}\text { U.S.A. } \\
(\mathrm{N}=76)\end{array}$ & P VALUE \\
\hline \multicolumn{4}{|l|}{ Nursing home residents } \\
\hline Age, mean (SD) & $85.1(5.8)$ & $81.4(6.6)$ & 0.001 \\
\hline Female, \% & 80 & 46 & $<0.001$ \\
\hline $\begin{array}{l}\text { Dementia severity, mean } \\
\text { BANS-S score (SD) }\end{array}$ & $18.6(3.5)$ & $21.3(4.4)$ & $<0.001$ \\
\hline Fully dependent in eating, $\%$ & 33 & 57 & 0.012 \\
\hline Fully dependent in walking, \% & 54 & 65 & 0.22 \\
\hline Fully dependent in dressing, $\%$ & 85 & 78 & 0.29 \\
\hline \multicolumn{4}{|c|}{ Family caregivers (respondents) } \\
\hline Female, \% & 61 & 74 & 0.13 \\
\hline \multicolumn{4}{|l|}{$\begin{array}{l}\text { Relationship to nursing home } \\
\text { resident, } \%\end{array}$} \\
\hline - spouse & 11 & 64 & $<0.001^{*}$ \\
\hline - son or daughter & 65 & 34 & \\
\hline - other & 24 & 1 & \\
\hline
\end{tabular}

* Spouse versus all others (son or daughter and other).

$\mathrm{SD}=$ Standard Deviation; BANS-S = Bedford Alzheimer Nursing Severity-Scale (range 7-28). 
Table 2. Satisfaction With Care (SWC) scores over residents' last 3 months of life

\begin{tabular}{|c|c|c|c|}
\hline MEAN SCORES（SD） & $\begin{array}{l}\text { NETHERLANDS } \\
(\mathrm{N}=54)\end{array}$ & $\begin{array}{l}\text { U.S.A. } \\
(\mathrm{N}=76)\end{array}$ & P VALUE \\
\hline \multirow[t]{2}{*}{ SWC total score: possible range $=10$ (worst) -40 (best) } & $31.9(4.7)$ & $30.4(6.1)$ & \\
\hline & $\begin{array}{l}\text { Observed range: } \\
\quad 22-40\end{array}$ & $\begin{array}{l}\text { Observed range: } \\
13-40\end{array}$ & 0.14 \\
\hline \multicolumn{4}{|l|}{ SWC item scores: possible range $=1$ (worst) -4 (best) } \\
\hline 1 I felt fully involved in all decision making & $3.4(0.65)$ & $3.3(0.82)$ & 0.57 \\
\hline $\begin{array}{l}2 \text { I would probably have made different decisions if I had } \\
\text { had more information* } \dagger\end{array}$ & $3.3(0.63)$ & $2.9(0.92)$ & 0.009 \\
\hline $\begin{array}{l}3 \text { All measure were taken to keep my care recipient } \\
\text { comfortable }\end{array}$ & $3.3(0.63)$ & $3.3(0.77)$ & 0.80 \\
\hline 4 The healthcare team was sensitive to my needs and feelings & $3.3(0.54)$ & $3.2(0.77)$ & 0.41 \\
\hline 5 I did not really understand my care recipient's condition* & $3.2(0.72)$ & $3.1(0.79)$ & 0.52 \\
\hline $\begin{array}{l}6 \text { I always knew which doctor or nurse was in charge of my } \\
\text { care recipient's care }\end{array}$ & $2.7(0.81)$ & $2.9(0.85)$ & 0.34 \\
\hline $\begin{array}{l}7 \text { I feel that my care recipient got all necessary nursing } \\
\text { assistance }\end{array}$ & $3.3(0.63)$ & $2.9(0.87)$ & 0.008 \\
\hline $8 \mathrm{I}$ felt that all medication issues were clearly explained to me & $2.9(0.76)$ & $3.0(0.84)$ & 0.50 \\
\hline $\begin{array}{l}9 \text { My care recipient received all treatments or interventions } \\
\text { that he or she could have benefited from }\end{array}$ & $3.2(0.68)$ & $2.9(0.88)$ & 0.066 \\
\hline $\begin{array}{l}10 \text { I feel that my care recipient needed better medical care at } \\
\text { the end of his or her life* }\end{array}$ & $3.3(0.68)$ & $2.9(0.79)$ & 0.005 \\
\hline
\end{tabular}

*Recoded so that higher score means better satisfaction.

$\dagger$ Missing item values were max. 7\% for Dutch data $(n=50-54$ Dutch) and max. 4\% for U.S. data $(n=73-76)$ except for this item, which had the highest percentage of missing values in both studies: $20 \%(11 / 54)$ rated not applicable for Dutch residents, and for U.S. residents, four were rated not applicable and additionally two were missing, totaling $8 \%$.

There were no missing total scores (imputed with subject means for or a maximum of three items missing).

Note: Cronbach's $\alpha$ was 0.91 for U.S. data and 0.87 for Dutch data. $\mathrm{SD}=$ standard deviation.

Table 3. Symptom Management (SM) scores over the residents' last 3 months of life

\begin{tabular}{|c|c|c|c|}
\hline MEAN SCORES（SD） & $\begin{array}{l}\text { NETHERLANDS } \\
(\mathrm{N}=54)\end{array}$ & $\begin{array}{l}\text { U.S.A. } \\
(\mathrm{N}=76)\end{array}$ & P VALUE \\
\hline SM total score & $29.1(9.2)$ & $20.4(10.6)$ & $<0.001$ \\
\hline $\begin{array}{l}\text { Possible range: } 0 \text { (worst) - } \\
45 \text { (best) }\end{array}$ & Observed range: $6-45$ & Observed range: $2-42$ & \\
\hline \multicolumn{4}{|l|}{ SM item scores } \\
\hline \multicolumn{4}{|c|}{ Possible range: 0 (worst) -5 (best)* } \\
\hline 1 Pain & $2.4(2.0)$ & $2.0(2.0)$ & 0.28 \\
\hline 2 Shortness of breath & $3.3(2.0)$ & $2.7(2.1)$ & 0.10 \\
\hline 3 Skin breakdown & $4.3(1.5)$ & $2.9(2.0)$ & $<0.001$ \\
\hline 4 Calm & $4.3(1.3)$ & $3.6(1.8)$ & 0.029 \\
\hline 5 Depression & $3.1(1.9)$ & $1.5(2.0)$ & $<0.001$ \\
\hline 6 Fear & $3.0(2.0)$ & $2.2(2.2)$ & 0.048 \\
\hline 7 Anxiety & $2.7(1.8)$ & $1.5(1.9)$ & 0.001 \\
\hline 8 Agitation & $3.1(1.8)$ & $1.6(1.9)$ & $<0.001$ \\
\hline 9 Resistance to care & $3.0(1.9)$ & $2.3(2.1)$ & 0.010 \\
\hline
\end{tabular}

* All items, except for "calm" were recoded so that a higher score implies better symptom management. Missing values varied between $2 \%$ and $7 \%(\mathrm{n}=50-53)$ for Dutch residents and varied between $11 \%$ and $24 \%(n=58-68)$ for U.S. residents.

Total scores (imputed with subject means for or a maximum of two items missing) refer to 52 Dutch cases (4\% missing) and 62 U.S. cases (18\% missing).

Note: Cronbach's $\alpha=0.76$ for US data and 0.72 for Dutch data. 
Table 4. Comfort assessment in dying (CAD) in nursing home residents

\begin{tabular}{|c|c|c|c|}
\hline MEAN SCORES (SD) & $\begin{array}{l}\text { NETHERLANDS } \\
(\mathrm{N}=54)\end{array}$ & $\begin{array}{l}\text { U.S.A. } \\
(\mathrm{N}=76)\end{array}$ & P VALUE \\
\hline CAD total score & $32.0(5.4)$ & $30.5(5.9)$ & 0.18 \\
\hline Possible range: 14 (worst) -42 (best) & $\begin{array}{l}\text { Observed range: } \\
18-41\end{array}$ & $\begin{array}{l}\text { Observed range: } \\
18-42\end{array}$ & \\
\hline \multicolumn{4}{|l|}{ CAD item scores } \\
\hline \multicolumn{4}{|l|}{ Possible range: 1 (worst) -3 (best)* } \\
\hline 1 Discomfort & $2.1(0.72)$ & $2.0(0.71)$ & 0.27 \\
\hline 2 Pain & $2.1(0.78)$ & $2.2(0.74)$ & 0.65 \\
\hline 3 Restlessness & $1.9(0.69)$ & $2.1(0.75)$ & 0.30 \\
\hline 4 Shortness of breath & $2.1(0.78)$ & $2.0(0.83)$ & 0.39 \\
\hline \multicolumn{4}{|l|}{ CAD subscale 1: } \\
\hline Physical Distress (items 1-4) & $8.3(1.8)$ & $8.4(2.3)$ & 0.92 \\
\hline 5 Choking & $2.4(0.70)$ & $2.3(0.80)$ & 0.56 \\
\hline 6 Gurgling & $2.4(0.76)$ & $2.3(0.79)$ & 0.57 \\
\hline 7 Difficulty swallowing & $2.0(0.86)$ & $1.7(0.84)$ & 0.039 \\
\hline \multicolumn{4}{|l|}{ CAD subscale 2: } \\
\hline Dying Symptoms (items 4-7) & $8.9(2.0)$ & $8.5(2.4)$ & 0.35 \\
\hline 8 Fear & $2.3(0.75)$ & $2.4(0.71)$ & 0.69 \\
\hline 9 Anxiety & $2.4(0.68)$ & $2.2(0.75)$ & 0.18 \\
\hline 10 Crying & $2.8(0.41)$ & $2.6(0.65)$ & 0.11 \\
\hline 11 Moaning & $2.3(0.74)$ & $2.5(0.68)$ & 0.15 \\
\hline \multicolumn{4}{|l|}{ CAD subscale 3: } \\
\hline Emotional Distress (items 8-11) & 9.7 (1.9) & $9.9(2.3)$ & 0.76 \\
\hline 12 Serenity & $2.3(0.74)$ & $1.9(0.69)$ & 0.021 \\
\hline 13 Peace & $2.4(0.72)$ & $2.1(0.67)$ & 0.015 \\
\hline 14 Calm & $2.4(0.67)$ & $2.1(0.74)$ & 0.016 \\
\hline \multicolumn{4}{|l|}{ CAD subscale 4: } \\
\hline Well Being (items 12-14) & $7.1(1.8)$ & $6.0(1.9)$ & 0.005 \\
\hline
\end{tabular}

* All items, except for "serenity," "peace," and "calm" were recoded so that a higher score means better symptom management.

Missing values were a max. of $6 \%(n=51-54)$ for Dutch residents and varied between $17 \%$ and $29 \%(n=54-63)$ for U.S. residents. Total scores (imputed with subject means for a maximum of four items missing) refer to 53 Dutch cases ( $2 \%$ missing) and 53 U.S. cases ( $30 \%$ missing).

Note: Cronbach's $\alpha=0.87$ for U.S. residents and 0.80 for Dutch residents.

were less frequently fully dependent with eating. Respondents in the U.S. sample were more frequently spouses.

\section{Satisfaction With Care}

Satisfaction With Care (SWC) scale total scores were not significantly different between the Dutch and U.S. studies $(\mathrm{p}=0.14)$. Table 2 shows mean total scores of $31.9, \mathrm{SD} 4.7$ versus 30.4 , SD 6.1 respectively, from which follows a beta coefficient (SWC score mean difference) for the Netherlands versus the U.S.A. of +1.5 (CI $-0.47-3.4)$. Adjusted for dementia severity, gender of resident and respondent, resident's age, and respondent being a spouse, the coefficient for the Netherlands as a country was somewhat larger but still not significant for the SWC scale $(+1.9, \mathrm{CI}-0.62-4.4)$.

However, scores of three of the ten items were significantly different $(p<0.01)$, with higher ratings for Dutch than for U.S. residents. (We report parametrical item test results because non-parametrical results hardly differed.) These items included generally worded items on nursing assistance (item 7) and on medical care (10). The last item (2) referred to a lack of information and regret of decisions taken. This item was, however, frequently rated "not applicable," especially by Dutch families (20\% versus $8 \%$ in U.S. families). One of the most specific items, on knowing the health care provider in charge (6) was rated lowest in both countries.

\section{Symptom Management}

Symptom Management (SM; Table 3) total scores were significantly higher for Dutch residents than for U.S. residents (29.1, SD 9.2 versus 20.4, SD 10.6; beta +8.7 ; CI 5.0-12.5), as were four of nine item scores (skin breakdown, depression, anxiety, and agitation). After adjustment, the mean 
difference between Dutch and U.S. SM scores remained the same (beta +8.7 ; CI 4.0-13.5).

\section{Comfort Assessment in Dying}

Comfort Assessment in Dying (CAD; Table 4) total scores showed no differences (32.0, SD 5.4 versus 30.5, SD 5.9; beta for the Netherlands versus the US +1.5, CI -0.69-3.7), and nor did the scores of any of the 14 items. The lack of difference in total CAD scores remained after adjustment (beta +1.0 ; CI -1.8-3.9).

However, the CAD "well Being" subscale was rated more favorably for Dutch residents (7.1, SD 1.8 versus 6.0 , SD 1.9 ; beta +1.1 , CI $0.32-1.8$; adjusted beta +1.3 , CI $0.26-2.2$ ).

\section{Associations with EOLD scores}

The SWC total score, adjusted for country, was most strongly associated with dementia severity. Family caregivers of residents with more severe dementia tended to be more satisfied with care (beta +0.22 per BANS-S 1-point increment, CI $-0.02-0.46 ; p=0.08)$. Nursing home of preference was significantly associated with satisfaction in the Dutch dataset. The mean SWC for home of preference was 3.3 points higher (33.0 versus 29.7; beta +3.3; CI 0.78-5.8).

The SM total score held the strongest association with the respondent being a spouse (adjusted for country). Spouses tended to provide higher ratings (beta +3.8, CI -0.61-8.1, p=0.09) than other respondents. None of the examined variables was associated with total CAD scores.

\section{Discussion}

Our results show a consistent pattern of small differences between ratings of the EOLD scales in the U.S. study and the Dutch study. Although we did not find very large differences between the ratings of Dutch and U.S. families, any significant difference we found either in total scores, subscale scores or items scores was consistently more favorable for end of life in the Dutch study. This was more obvious for the SM and CAD scales than for the SWC scale. This suggests that at least the SM and CAD scales of the EOLD scales may be sensitive to differences between countries or, alternatively (or in addition), to differences in time frames given the difference of about seven years between the two studies. Nevertheless, the pattern of consistent differences suggests that the EOLD $S M$ and CAD scales are valid scales to use in assessing differences in quality of dying.
Further, exploring associations of total scores with other variables, we found that proxy respondents of residents with more severe dementia tended to provide higher SWC scores, and that respondents where the resident died in the nursing home of preference were more satisfied. Spouses tended to provide higher SM scores than other respondents.

\section{Symptoms and comfort}

Dutch residents suffered from fewer symptoms in the last months of life and had higher levels of wellbeing when dying according to the family caregivers. Our finding of different quality of dying raises the question of whether there were any differences between the quality of care provided. This may refer to differences in care between the two countries. It is also possible that our results represent some cohort (time) effect if treatments to relieve symptoms are increasingly provided in the U.S.A. as they have been in the Netherlands between 1996-1998 and 2006-2007 (van der Steen et al., 2009). More recently published U.S. data of SM and CAD mean total scores, from an ongoing prospective study on care for residents with advanced dementia (CASCADE; Boston area), were higher indeed (SM: 36.4, SD 7.8 and CAD: 33.6, SD 5.0) (Kiely et al., 2006). However, they are not comparable because the SM scores did not refer to end of life while CAD scores referred to the last week of life which may be more inclusive than the dying phase per se. Further, data were obtained from nurses by face-to-face interview, potentially introducing bias in favor of better symptom management, although in our Dutch data, we did not find evidence of such phenomenon. Further exploration of the Dutch data did not reveal any time trends between 2005 and 2007. We conclude that the observed consistent patterns cannot be linked with certainty to either differences between countries or improvements of care over time, but the EOLD consistently captured these differences, as it captured differences between settings within the U.S.A. (Volicer et al., 2003).

\section{Satisfaction with care}

Interpreting satisfaction with care results may present difficulties that are inherent to instruments that measure satisfaction with care. Significant differences between the Netherlands and the U.S.A. were found only in two generally-worded items on nursing care and medical care, and in an item on decision-making that suggested that the respondent made decisions on her/his own. This item was frequently rated as "not applicable" and may not apply well to a shared decision-making model employed in the Netherlands (Helton et al., 
2006). Reported mean SWC scores in CASCADE were not obtained during the last three months of life, but were nevertheless very similar to those we found in our study $(31.9$, SD 4.7 in the Netherlands, and 30.4, SD 6.1 in the U.S.A): 31.0, SD 4.2 (Engel et al., 2006) and 30.9, SD 4.1 in a broader sample (Kiely et al., 2006).

Measures of satisfaction with care have been criticized for not being very sensitive due to the dependency on respondents' expectations and other unmeasured factors (Williams, 1994). It is possible that total mean scores are not suitable for comparison between countries because respondents' expectations of care may vary according to the standards of care, implying circularity and regression to the mean within each country. In fact, dying in the preferred home contains a substantial expectation component, and the possibility of dying in the place of preference may vary according to country-specific policies. Anecdotal evidence in our ongoing study (van der Steen et al., 2007a; 2008b) and in various other studies (Turris, 2005) suggests that respondents are hesitant to be critical, tending to express understanding for hard working nurses. Lubart et al. (2004) found that three-quarters of Israeli representatives of residents with dementia rated satisfaction with care as a 5 on a $1-5$ scale. They suggested that guilt over leaving the care to others or reluctance to be involved in care and admiring the efforts of staff in dealing with difficult behaviors might also explain high satisfaction with care scores. This may also explain our finding of a tendency to be more satisfied with care for more severely demented dying residents. Although we found no ceiling effect with the EOLD-SWC scores, cross-country samples present a complex mix of expectations and feelings that may well result in a tendency to produce relatively stable and high mean overall SWC scores in spite of differences in care between countries.

\section{Associations}

In using the EOLD scales across different settings and different case mixes, it is preferable that the outcome is not overly dependent on respondents' and residents' characteristics or, alternatively, that one can adjust for known correlates, especially if the outcome measures are in fact used as indicators of quality of care. Our study suggests that nursing home of preference, severe dementia and rating by a spouse all influence EOLD scores. Several studies have examined associations of representatives' satisfaction with care scores. In a recent U.S. study, male respondents tended to be more satisfied with communications with professional caregivers, although differences were not significant (Biola et al., 2007). Further, daughters tended to be more critical. In our study we did not find such an association with SWC scores, although there was a non-significant $(\mathrm{p}=0.14)$ tendency for daughters to give lower SM ratings $(-2.9, \mathrm{CI}-6.9-0.99)$.

\section{Study limitations}

Our study is limited by the U.S. data being older, and by the small sample sizes, which limits the power to detect differences between studies. Further, family perspectives present an important, but just a single view. For example, Berlowitz et al. (1995) examined the correspondence between the rating of quality of life domains by nursing home residents' self-reports and nurses' and physicians' ratings and found that physical function and in general, more directly observable symptoms corresponded best with resident selfreport. However, it was found that mean scores between families and nurses did not differ much, in spite of poor to moderate agreement of family individual CAD and SM scores with nurses scores (Rich et al., 2007).

The Dutch study was not nationally representative, and $37 \%$ of cases were enrolled in "anthroposophic" Dutch nursing homes deploying a specific philosophy of life. These homes had higher SM and CAD scores than the traditional homes in the study. Although this may have resulted in an overestimation of cross-national differences, any item which Dutch families rated significantly more favorably than U.S. families was consistently scored higher (in absolute values) in Dutch traditional homes compared with U.S. nursing homes.

Reconciling different study designs is crucial for any cross-national pooling of data (van der Steen et al., 2008a). The U.S. and Dutch studies in our comparison both employed a mortality followback design with written surveys for families and equal time-windows, although there was variability in time of assessment after death (two months versus "within a year"). Few studies have examined effects of timing of questionnaires after death on proxies' recollection (McPherson and AddingtonHall, 2003). Casarett et al. (2003) showed that responses to satisfaction surveys undertaken at two weeks and six weeks post-death were identical.

\section{Conclusions and implications for further study}

The EOLD scales may be used to compare end of life of nursing home residents with dementia across different nations, if confirmed in other studies. This refers to the SM and CAD scales; further work is needed to determine if and how the SWC scale 
or specific items can complement this. We further recommend the use not only of overall means but also of item scores and the need to adjust for potential confounders.

Ongoing work will determine how the EOLD scales are related to other end-of-life scales that are being applied to nursing home residents with dementia and how these measures relate conceptually to quality of care and quality or experience of dying. Our findings can inform future comparisons between ongoing and new prospective studies such as those performed in the U.S.A., the Netherlands, Israel, and Belgium (van der Steen et al., 2007a; 2008b), employing similar designs and time frames. Combined studies will allow researchers to examine system-level factors affecting end of life as in a "natural experiment," and, by comparing outcomes directly, to identify opportunities for improving care (Higginson, 2005; van der Steen et al., 2008a). This will ultimately inform intervention studies in each setting, where the EOLD scales may be used as an outcome.

\section{Conflict of interest}

None.

\section{Description of authors' roles}

The study was conceived and designed by J. T. van der Steen, M-J Gijsberts, M. T. Muller and L. Volicer. The data were collected by M-J Gijsberts and L. Volicer; analyzed by J. T. van der Steen; and interpreted by J. T. van der Steen, M-J Gijsberts, M. T. Muller, L. Deliens and L. Volicer. Early drafts of the paper were written by J. T. van der Steen; all the authors provided critical and important intellectual content during the revision stage and all approved the final paper.

\section{Acknowledgments}

This study was supported by the VU University Medical Center, EMGO Institute, Departments of Nursing Home Medicine and Department of Public and Occupational Health, Amsterdam, the Netherlands, and by a career award for JTS of the Netherlands Organisation for Scientific Research (NWO, The Hague; Veni 916.66.073).

\section{References}

Aminoff, B. Z., Purits, E., Noy, S. and Adunsky, A. (2004). Measuring the suffering of end-stage dementia: reliability and validity of the Mini-Suffering State Examination. Archives of Gerontology and Geriatrics, 38, 123-130.

Bellelli, G., Frisoni, G. B., Bianchetti, A. and Trabucchi, M. (1997). The Bedford Alzheimer Nursing Severity scale for the severely demented: validation study. Alzheimer Disease and Associated Disorders, 11, 71-77.

Berlowitz, D. R., Du, W., Kazis, L., Lewis, S. (1995). Health-related quality of life of nursing home residents: differences in patient and provider perceptions. Fournal of the American Geriatrics Society, 43, 799-802.

Biola, H., Sloane, P. D., Williams, C. S., Daaleman, T. P., Williams, S. W. and Zimmerman, S. (2007). Physician communication with family caregivers of long-term care residents at the end of life. Fournal of the American Geriatrics Society, 55, 846-856.

Brandt, H. E., Deliens, L., van der Steen, J. T., Ooms, M. E., Ribbe, M. W. and van der Wal, G. (2005). The last days of life of nursing home residents with and without dementia assessed with the palliative care outcome scale. Palliative Medicine, 2005, 19, 334-342.

Caprio, A. J. et al. (2008). Pain, dyspnea, and the quality of dying in long-term care. Fournal of the American Geriatrics Society, 56, 683-688.

Casarett, D. J., Crowley, R., Hirschman, K. B. (2003). Surveys to assess satisfaction with end-of-life care: does timing matter? Fournal of Pain and Symptom Management, $25,128-132$.

Engel, S. E., Kiely, D. K. and Mitchell, S. L. (2006). Satisfaction with end-of-life care for nursing home residents with advanced dementia. Fournal of the American Geriatrics Society, 54, 1567-1572.

Gijsberts, M. J. H. E., van der Steen, J. T., Muller, M. T. and Deliens, L. (2008). [End-of-life with dementia for residents of anthroposophic and traditional Dutch nursing homes]. Tijdschrift voor Gerontologie en Geriatrie, 39, 256-264 [in Dutch].

Hales, S., Zimmermann, C. and Rodin, G. (2008). The quality of dying and death. Archives of Internal Medicine, $168,912-918$.

Hearn, J. and Higginson, I. J. (1999). Development and validation of a core outcome measure for palliative care: the palliative care outcome scale. Palliative Care Core Audit Project Advisory Group. Quality in Health Care, 8, 219-227.

Helton, M. R., van der Steen, J. T., Daaleman, T. P., Gamble, G. R. and Ribbe, M. W. (2006). A cross-cultural study of physician treatment decisions for demented nursing home patients who develop pneumonia. Annals of Family Medicine, 4, 221-227.

Higginson, I. J. (2005). End-of-life care: lessons from other nations. Fournal of Palliative Medicine, 8 (Suppl. 1), S161-S173.

Hoek, J. F., Penninx, B. W., Ligthart, G. J. and Ribbe, M. W. (2000). Health care for older persons, a country profile: the Netherlands. Fournal of the American Geriatrics Society, 48, 214-217.

Kiely, D. K., Volicer, L., Teno, J., Jones, R. N., Prigerson, H. G. and Mitchell, S. L. (2006). The validity and reliability of scales for the evaluation of end-of-life care in advanced dementia. Alzheimer Disease and Associated Disorders, 20, 176-181. 
Lubart, E. et al. (2004). Satisfaction with the care of institutionalized psychogeriatric patients, as reflected by a survey of their relatives. Archives of Gerontology and Geriatrics, 38, 45-50.

McPherson, C. J. and Addington-Hall, J. M. (2003). Judging the quality of care at the end of life: can proxies provide reliable information? Social Science and Medicine, 56, 95-109.

Mitchell, S. L., Teno, J. M., Miller, S. C. and Mor, V. (2005). A national study of the location of death for older persons with dementia. Fournal of the American Geriatrics Society, 53, 299-305. Erratum in: Fournal of the American Geriatrics Society, 2005, 53, 741.

Mitchell, S. L., Kiely, D. K., Jones, R. N., Prigerson, H., Volicer, L. and Teno, J. M. (2006). Advanced dementia research in the nursing home: the CASCADE study. Alzheimer Disease and Associated Disorders, 20, 166-175.

Munn, J. C. et al. (2007). Measuring the quality of dying in long-term care. Fournal of the American Geriatrics Society, $55,1371-1379$

Rich, S., Williams, C. and Zimmerman, S. (2007). Family-staff member agreement in reports about end of life in assisted living and nursing homes. The Gerontologist, 47 (Special No. 1), 158. Abstract.

Steel, K. et al. (2003). The RAI-PC: an assessment instrument for palliative care in all settings. American fournal of Hospice and Palliative Care, 20, 211-219.

Stewart, A. L., Teno, J., Patrick, D. L. and Lynn, J. (1999). The concept of quality of life of dying persons in the context of health care. Fournal of Pain and Symptom Management, 17, 93-108.

Teno, J. (2000). Toolkit of Instruments to Measure End-of-Life Care. After-Death Bereaved Family Interview: Nursing Home Version. http://www.chcr.brown.edu/pcoc/ linkstoinstrumhtm.htm.

Turris, S. A. (2005). Unpacking the concept of patient satisfaction: a feminist analysis. Fournal of Advanced Nursing, 50, 293-298.

van der Steen, J. T. et al. (2004). Treatment of nursing home residents with dementia and lower respiratory tract infection in the United States and in the Netherlands: an ocean apart. Fournal of the American Geriatrics Society, 52, 691-699.

van der Steen, J., Ribbe, M., Deliens, L., Koopmans, R. and Onwuteaka-Philipsen, B. (2007a). End of life with dementia and prospective studies. The Gerontologist, 47 (Special No. 1), 169-170. Abstract.

van der Steen, J. T. and Ribbe, M. W. (2007b). Sterven met dementie: wat weten wij ervan? [Dying with dementia: what do we know about it?] Tijdschrift voor Gerontologie en Geriatrie, 38, 288-297 [in Dutch].

van der Steen, J. T., Kruse, R. L., van der Wal, G., Mehr, D. R. and Ribbe, M. W. (2007c). [Treatment of pneumonia in nursing home residents with severe dementia: for residents with poor prognosis, a more reserved approach in The Netherlands and more active treatment in the United States]. Nederlands Tijdschrift voor Geneeskunde, 151, 915-919 [in Dutch].

van der Steen, J. T. et al. (2008a). Benefits and pitfalls of pooling datasets from comparable observational studies: combining US and Dutch nursing home studies. Palliative Medicine, 22, 750-759.

van der Steen, J. T. et al. (2008b). Treatments in patients dying with dementia: a cross-cultural perspective. Fournal of the American Geriatrics Society, 56, 565-567.

van der Steen, J. T., Gijsberts, M-J. H. E., Knol, D. L., Deliens, L. and Muller, M. T. (2009). Ratings of symptoms and comfort in dementia patients at the end of life: comparison of nurses and families. Unpublished paper, obtainable from corresponding author. VU University Medical Center, EMGO Institute, Amsterdam.

Volicer, L., Hurley, A. C., Lathi, D. C. and Kowall, N. W. (1994). Measurement of severity in advanced Alzheimer's disease. Fournal of Gerontology, 49, M223-M226.

Volicer, L., Hurley, A. C. and Blasi, Z. V. (2001). Scales for evaluation of end-of-life care in dementia. Alzheimer Disease and Associated Disorders, 15, 194-200.

Volicer, L., Hurley, A. C. and Blasi, Z. V. (2003). Characteristics of dementia end-of-life care across care settings. American fournal of Hospice and Palliative Care, 20, 191-200.

Williams, B. (1994). Patient satisfaction: a valid concept? Social Science and Medicine, 38, 509-516. 